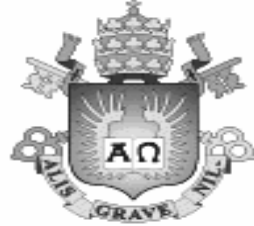

Maria da Conceição Calmon Arruda

\title{
A Reforma do Ensino Médio Técnico: democratização ou cerceamento?
}

Tese de Doutorado

Tese apresentada ao Programa de PósGraduação em Educação Brasileira da PUC-Rio como requisito parcial à obtenção do título de Doutor em Educação Brasileira.

Orientador: Leandro Augusto Marques Coelho Konder.

Rio de Janeiro

Dezembro de 2007 


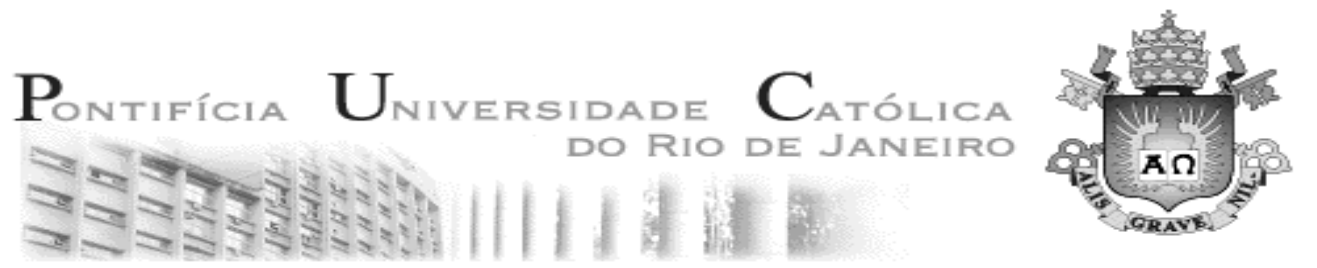

MARIA DA CONCEIÇÃO CALMON ARRUDA

\author{
A Reforma do Ensino Médio Técnico: \\ democratização ou cerceamento?
}

\begin{abstract}
Tese apresentada como requisito parcial para obtenção do grau de Doutor pelo Programa de PósGraduação em Educação do Departamento de Educação do Centro de Teologia e Ciências Humanas da PUC-Rio. Aprovada pela Comissão Examinadora abaixo assinada.
\end{abstract}

Prof ${ }^{\circ}$. Leandro Augusto Marques Coelho Konder

Orientador PUC-Rio

Prof ${ }^{\circ}$. Ralph Ings Bannell Presidente PUC-Rio

Prof ${ }^{\mathrm{a}}$. Alicia Maria Catalano de Bonamino PUC-Rio

Prof. Gaudêncio Frigotto UERJ

Prof $^{a}$. Marise Nogueira Ramos

UERJ

Prof. Paulo Fernando Carneiro de Andrade Coordenador Setorial do Centro de Teologia e Ciências Humanas

PUC-Rio

Rio de Janeiro, 11 dezembro de 2007 
Todos os direitos reservados. É proibida a reprodução total ou parcial do trabalho sem autorização do autor, do orientador e da universidade.

\section{Maria da Conceição Calmon Arruda}

Graduou-se em Biblioteconomia na UNI-RIO (Universidade do Rio de Janeiro) em 1988. Mestre em Ciência da Informação pela UFRJ (Universidade Federal do Rio de Janeiro) em 1999.

Ficha Catalográfica

Arruda, Maria da Conceição Calmon

A reforma do ensino médio técnico : democratização ou cerceamento? / Maria da Conceição Calmon Arruda ; orientador: Leandro Augusto Konder. - 2007. 185 f. ; $30 \mathrm{~cm}$

Tese (Doutorado em Educação)-Pontifícia Universidade Católica do Rio de Janeiro, Rio de Janeiro, 2007. Inclui bibliografia

1. Educação - Teses. 2. Reforma do ensino médio técnico. 3. Ensino médio técnico. 4. Trabalho-educação. I. Konder, Leandro Augusto. II. Pontifícia Universidade Católica do Rio de Janeiro. Departamento de Educação. III. Título. 
A José e Hilda que sempre trabalharam e me inspiraram. A Júlio e Maurício, que mesmo sem saber, estão buscando seu lugar no mundo. 


\section{Agradecimentos}

Ao professor Leandro Konder, pela generosidade e pela atenção que me dispensou durante o processo de orientação.

À PUC-Rio, pela concessão da bolsa de isenção que viabilizou este estudo.

Aos professores do Programa de Pós-Graduação em Educação, com quem tive a oportunidade de conviver ao longo do curso, especialmente aos professores Ralph Ings Bannell, Zaia Brandão, Alicia Bonamino e Rosália Duarte.

Aos amigos e professores Lucília Lino de Paula e Donaldo Bello, pelo carinho e pela colaboração, sem os quais a caminhada teria sido mais árida.

Aos amigos do café do Leandro, em especial Rita Ribes, Wagner Braga e Clóvis.

Ao professor Giovani Gláucio, pelo apoio e dicas durante a tabulação dos questionários.

À minha irmã Cláudia Calmon, pela interlocução e disposição para a leitura.

Ao professor Paulo Oliveira, amigo de infância, que revisou este texto.

Aos amigos, pelo apoio e pelo afeto, especialmente Ana Maria, Emiliana, Jorge, Reinaldo e Sandra.

Aos colegas de curso, Diana e Glauco, pelas sugestões.

Às escolas, que permitiram a realização da pesquisa e aos alunos que se dispuseram a participar desse estudo.

Aos funcionários do Departamento de Educação e da Biblioteca Central, pela gentileza e atenção. 


\section{Resumo}

Arruda, Maria da Conceição Calmon; Konder, Leandro Augusto Marques. A Reforma do ensino médio técnico: democratização ou cerceamento? Rio de Janeiro, 2007. 185p. Tese de doutorado - Departamento de Educação, Pontifica Universidade Católica do Rio de Janeiro.

A presente investigação sobre a reforma do ensino médio técnico dos anos 90 teve como pano de fundo as mudanças por que passa o mundo do trabalho e a relação hodierna entre trabalho e educação. O senso comum associa a educação como um elemento propulsor da competitividade dos países e dos indivíduos em um contexto de acirramento da competitividade intercapitalista e da adoção de uma série de políticas desfavoráveis a quem vive do trabalho. É neste contexto que a reforma do ensino médio técnico foi apresentada à sociedade brasileira, como uma medida que não só propiciaria a universalização do ensino médio, como a democratização do acesso dos alunos das camadas populares à rede federal de ensino técnico. A partir do questionamento da capacidade da arquitetura da reforma em contribuir para a democratização do acesso, realizamos uma pesquisa de cunho quantitativo com 302 alunos de três escolas técnicas da região metropolitana do Rio de Janeiro. Nossa interrogação inicial se desdobrou em três questões que permearam a pesquisa: (1) a reforma, longe de ter democratizado o acesso dos alunos das camadas populares ao ensino técnico federal, o teria colocado mais distante da realidade desses atores sociais, em função das dificuldades postas para cursar o ensino técnico; (2) a existência de escolas técnicas privadas destinadas às camadas médias seria um indicativo do interesse desse estrato social pelo ensino médio técnico e (3) o restabelecimento do sistema de ensino dual no secundário estaria associado não a um projeto de democratização do ensino, mas a uma concepção de educação que vê na formação para o trabalho a trajetória escolar mais adequada aos alunos das camadas populares. A título de conclusão destacamos que a concepção de educação norteadora da reforma, longe de ter um compromisso efetivo com a democratização do acesso das camadas populares ao sistema de ensino, buscou 
consolidar a educação profissional como o caminho natural desse estrato social; e afirmamos que as escolas técnicas federais não são escolas de elite porque têm como proposta uma formação para o trabalho, o que, independente das aspirações de seus alunos, vai estabelecer uma socialização diversa da proposta pelas escolas de elites.

\section{Palavras-chaves:}

Reforma do ensino médio técnico; ensino médio técnico; trabalho-educação. 


\section{Abstract}

Arruda, Maria da Conceição Calmon; Konder, Leandro Augusto Marques. A Reforma do ensino médio técnico: democratização ou cerceamento? Rio de Janeiro, 2007. 185p. Tese de doutorado - Departamento de Educação, Pontifica Universidade Católica do Rio de Janeiro.

The current investigation on the 90's secondary technical education reform emphasizes the changes occurred in the labor field as well as the present relationship between education and labor. The common sense associates education to a propelling element of competition of countries and individuals in an aggressive intercapitalist competitivity linked to the adoption of a series of unfavorable policies towards those who live on their work capacity. The secondary technical education reform was introduced to Brazilian society in this context, that is, it was a measure that not only would help universalizing secondary education, but also would democratize the access of students from lower classes to the federal network of technical schools. We argued, firstly, the architectural capacity of the reform in contributing to democratize the access by implementing a quantitative survey with 302 students who belonged to 3 technical schools of the metropolitan area of Rio de Janeiro. Our first concern was subdivided into three other ones: (1) the reform, instead of democratizing the access of lower class students to the federal schools, ended up by creating distances, due to the obstacles these students had regarding the difficulties they faced in attending the technical schools; (2) the existence of private technical schools that aimed at the middle class students would indicate the interest of this middle class in secondary technical education, and (3) the re-establishment of the dual system of education in the secondary levels would be associated not to a project of democracy in educational system but to a conception of education that understands the technical education as the most adequate issue to students from lower classes. As a conclusion we will affirm that is the conception of education that the reform embodies which, far from democratizing the access of the general public to the educational system, ended up, instead, by consolidating the professional education as a natural way to students from lower classes; and that the public technical schools aren't elite institutions as they focus on trainning their 
students to the jobmarket, what provides them with completely different experiences from those provided by the elite schools.

\section{Keywords:}

Reform of the secondary technical education; secondary technical education; labor-education. 


\section{Sumário}

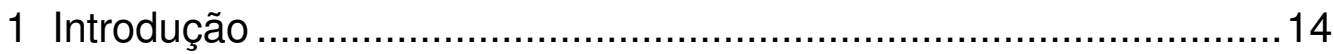

2 A Relação trabalho educação no cenário contemporâneo.................20

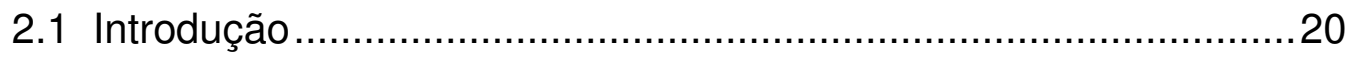

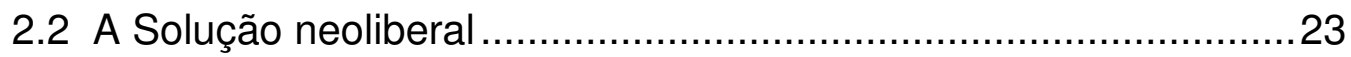

2.3 Liberdade $\mathrm{x}$ Igualdade na tradição liberal .....................................30

2.4 A Emergência de um novo tipo humano? ......................................34

2.5 Algumas considerações ......................................................... $4 \underline{7}$

3 A Posição do Brasil no sistema capitalista ........................................51

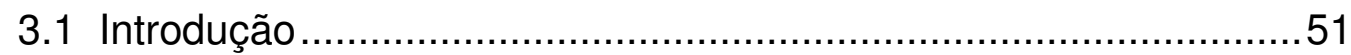

3.2 O Brasil e as três revoluções industriais ........................................

3.3 O Trabalho na terceira revolução industrial ..................................69

3.4 Emprego e desemprego no Brasil nos anos 90: ação e reação ....72

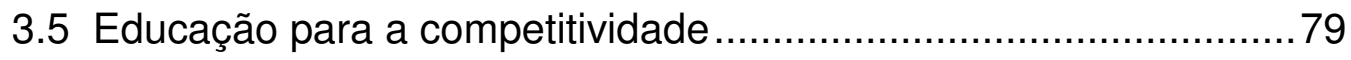

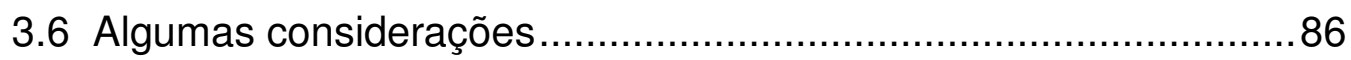

4 A Reforma do ensino médio técnico: ruptura ou adaptabilidade? ....88

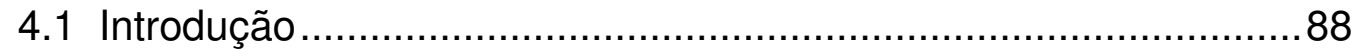

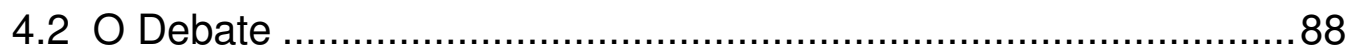

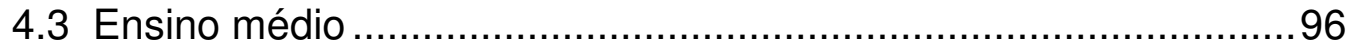

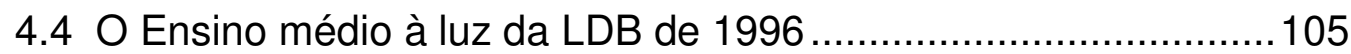

4.5 Os Pressupostos que nortearam a reforma ................................107

4.6 Decreto 2.208 de 17/04/1997: marco ou resultante? ...................119

4.7 A Reforma nas escolas técnicas federais ...................................125

4.8 O Decreto 5.154 de 2004 e o consenso possível .........................128

4.9 Algumas considerações ..........................................................130

5 A Reforma do ensino médio técnico: democratização ou

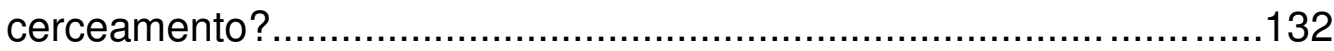

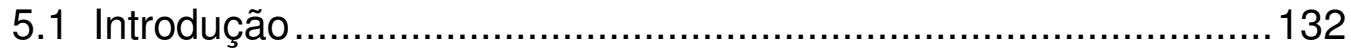


5.2 As Escolas.

137

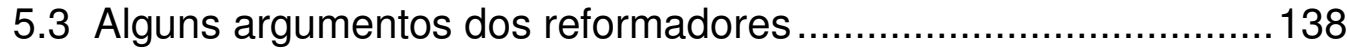

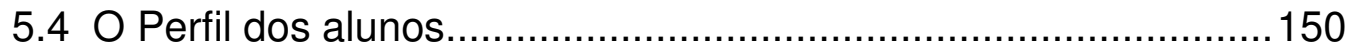

5.5 A Representação dos alunos de educação e de trabalho.............158

5.6 Algumas considerações ..............................................................168

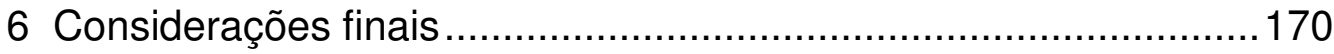

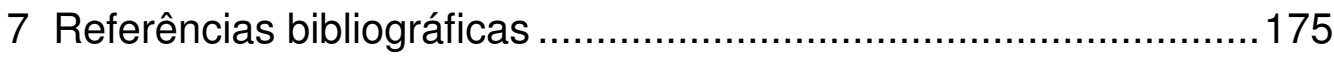




\section{Lista de Tabelas}

Tabela 1: Dados PNAD e matrículas no ensino médio em 2005............77

Tabela 2: O Ensino Médio no censo escolar 2004-2006 .......................78

Tabela 3: Relação escolas/alunos................................................. 135

Tabela 4: Algumas ocupações típicas dos estratos socioocupacionais136

Tabela 5: Estratificação socioocupacional dos pais por escola............141

Tabela 6: Estratificação socioocupacional das mães por escola..........142

Tabela 7: Renda familiar ......................................................... 142

Tabela 8: Escolaridade dos pais por escola..................................145

Tabela 9: Escolaridade das mães por escola...............................145

Tabela 10: Ensino Fundamental................................................ 151

Tabela 11: Distribuição dos alunos por local de residência..................152

Tabela 12: Avaliação da concomitância por escola..............................155

Tabela 13: Cursos técnicos oferecidos pelas escolas .........................156

Tabela 14: Áreas profissionais ................................................. 157 


\section{Lista de Siglas e Abreviaturas}

BID - Banco Interamericano de Desenvolvimento.

C\&T - Ciência e Tecnologia.

CBO - Classificação Brasileira de Ocupações.

CEB- Câmara de Educação Básica

CEDERJ - Centro de Educação a Distância do Estado do Rio de Janeiro.

CEFET - Centro Federal de Educação Tecnológica.

CNE - Conselho Nacional de Educação.

ENEM - Exame Nacional do Ensino Médio.

FAT - Fundo de Amparo ao Trabalhador.

FHC - Fernando Henrique Cardoso

FUNDEB - Fundo da Educação Básica.

GOTs - Ginásios Orientados para o Trabalho.

IFET - Instituto Federal de Educação, Ciência e Tecnologia.

JK - Juscelino Kubitschek

LDB - Lei de Diretrizes e Bases da Educação Nacional

P\&D - Pesquisa e Desenvolvimento

PDE - Plano de Desenvolvimento da Educação.

PIB - Produto Interno Bruto

PLANFOR - Plano Nacional de Qualificação do Trabalhador.

PNAD - Pesquisa Nacional por Amostra de Domicílio.

PNE - Plano Nacional de Educação.

PNQ - Plano Nacional de Qualificação.

PREAL - Programa de Promoção da Reforma Educativa na América Latina e Caribe.

PROEP - Programa de Expansão da Educação Profissional.

ProUni - Programa Universidade para Todos.

SENAI - Serviço Nacional de Aprendizagem Industrial.

SM - Salário mínimo nacional.

TICs - Novas Tecnologias de Informação e Comunicação. 